\title{
Fatty acid composition of white adipose tissue and breast milk of Mauritian and French mothers and erythrocyte phospholipids of their full-term breast-fed infants
}

\author{
Prity Pugo-Gunsam ${ }^{1,2}$, Philippe Guesnet ${ }^{1}$, Anwar Hussein Subratty ${ }^{2}$, Dev Anand Rajcoomar ${ }^{3}$, \\ Chantal Maurage ${ }^{1}$ and Charles Couet $^{1 *}$ \\ ${ }^{1}$ Unité de Recherche associée 'Lipides et Croissance', Université-INRA, Tours, France \\ ${ }^{2}$ Faculty of Science, Réduit, University of Mauritius, Mauritius \\ ${ }^{3}$ Jawaharlall Nehru Hospital, Ministry of Health, Mauritius
}

(Received 17 June 1998 - Revised 6 April 1999 - Accepted 23 April 1999)

\begin{abstract}
The fatty acid compositions of white adipose tissue, colostrum and mature milk triacylglycerols from Mauritian ( $n$ 13) and French ( $n$ 15) women were analysed and compared in order to highlight cultural differences in dietary intakes and their influence on milk fatty acid composition. Erythrocyte phosphatidylethanolamine and phosphatidylcholine fatty acid compositions were also investigated in their term infants, breast-fed over a period of 6 weeks. Fatty acid composition $(\mathrm{g} / 100 \mathrm{~g})$ of all samples was determined by GLC and anthropometric measurements were assessed in the two populations at birth and on day 42. Comparisons of white adipose tissue fatty acid compositions demonstrated lower levels of saturated (23.64 (SE 1.54) v. 29.75 (SE 0.67), $P<0.01$ ) and monounsaturated (39.44 (SE 1.27) v. 54.84 (SE 0.75), $P<0.001$ ) fatty acids and higher levels of polyunsaturated fatty acids ( $n-6$ series: 32.47 (SE 1.31) v. 14.32 (SE 0.47), $P<$ 0.001 and $n$-3 series: 2.87 (SE 0.49) v. 0.80 (SE 0.07), $P<0.01$ ) in Mauritian than in French samples respectively. Accordingly, milk fat of the Mauritian women contained higher levels of parent essential fatty acids and their longer-chain derivatives than did milk fat from French women. Higher levels of parent essential fatty acids but lower levels of long-chain polyunsaturated fatty acids were found in erythrocyte phospholipids of Mauritian infants compared with French infants. Infants' erythrocyte arachidonate and docosahexaenoate contents did not correlate with any anthropometric variables at birth or at day 42 , neither did they correlate with anthropometric variation over the study period. Our results suggest the lack of a simple relationship between the amount of long-chain polyunsaturated fatty acids in human milk and their accretion in the erythrocyte phospholipids of breast-fed infants when provided concomitantly with high levels of both linoleic and $\alpha$-linolenic acids in ratios which fall within recommended ranges.
\end{abstract}

Breast milk: White adipose tissue: Phospholipids

Human milk provides the parent essential fatty acids linoleic acid (18:2n-6) and $\alpha$-linolenic acid (18:3n-3) together with their long-chain derivatives with twenty to twenty-two $\mathrm{C}$ atoms. Both parent essential fatty acids and their longchain derivatives are found in variable amounts depending on the lipid composition of the maternal diet (Jensen, 1996; Innis et al. 1997). Other classes of fatty acids, such as saturated and monounsaturated fatty acids, vary over still wider ranges relative to the type of fat and proportions of lipid and carbohydrate in the maternal diet. For instance, it has been reported that in women on so-called Western diets, medium-chain fatty acids comprise about $10-12 \%$ of the milk fatty acids, while in other non-Western cultures, with low-fat and high-carbohydrate diets, they can be as high as $30 \%$ of the milk fatty acids (Neville \& Picciano, 1997).

To date, several studies have investigated the effects of different types of diets from non-Western populations on the fatty acid pattern of breast milk but, to our knowledge, there is only one study that has assessed the fatty acid composition of human milk from women of Indian origin living on the island of Penang (Kneebone et al. 1985). The study showed that the breast-milk fatty acid composition of these women was greatly influenced by their vegetarian diet and their high consumption of saturated coconut oil. Although the influence of maternal diet on milk fat composition is proven, and although there has been no previous indication 
to suggest that ethnicity brings about differences in the milk fatty acid composition, it was tempting to investigate milk fat composition in women belonging to the Indian ethnic group in the island of Mauritius, who share close cultural habits and vegetarian type diets with those living on the island of Penang. In contrast to the high dietary intake of coconut oil in the women from Penang island, Mauritian women consume soyabean-oil-rich diets. The triacylglycerol composition of white adipose tissue of mothers was also studied because it mirrors the qualitative aspects of dietary intake (Hirsch et al. 1960; Field et al. 1985). In addition, comparisons between Mauritian and French breast-milk and adipose-tissue samples were performed in order to highlight the effect of cross-cultural dietary differences with the prior assumption that the Indo-Mauritian diet is more representative of a vegetarian diet than the French diet. The second aim of the study was to investigate the effect that human milk from these two populations had on the fatty acid composition of erythrocyte phospholipids of healthy term-gestation infants breast-fed over a period of 6 weeks.

\section{Materials and methods}

\section{Subjects}

Before giving birth, healthy, volunteer Mauritian and French women planning to breast-feed entered a first selection. All volunteers attended an antenatal clinic regularly during their pregnancies. Their clinical reports attested perfectly normal ongoing pregnancies. All volunteers were interviewed and those taking drugs or having spontaneous selective diets or food fads were not included in the study. The Mauritian women and their full-term newborns lived in the district of Grand Port, Savanne. They belonged to the Indian ethnic group and were recruited at the Jawaharlall Nehru Hospital in Mauritius between August 1996 and April 1997. French women and their infants lived in the Loire Valley region of France and were recruited between March 1995 and March 1996. All French data, except those obtained for white adipose tissue have been previously reported (Maurage et al. 1998). Mauritian and French mothers were aged between 20 and 40 years and were on their usual mixed diets during pregnancy and lactation and no dietary modification had been proposed. All pregnancies and deliveries were normal and all newborns were healthy term-gestation infants $(>38$ and $<40$ weeks) with an appropriate weight for gestational age. The study period was designed over 6 weeks, because this is the usual period over which exclusive breastfeeding is practised in both populations and, furthermore, it corresponds to twice the half-life of docosahexaenoic acid in erythrocyte membrane phospholipids as reported by Connor et al. (1990).

The study was approved by the Ethics Committee of the Ministry of Health of Mauritius and the Ethics Committee of Tours Hospital, France. Informed and written consent was obtained from all participants.

\section{Experimental design}

The body weight, head circumference, crown-to-heel length and mid-arm circumference were recorded at birth and on day 42. All infants who had birth weights and head circumferences appropriate for gestational age based on growth curves reported by Sempe et al. (1979) were included in the study. The head circumference was measured at the largest occipitofrontal diameter and the mid-upper-arm circumference of the upper left arm was measured midway between the acromion and olecranon as reported by Sasanow et al. (1986). The measurements obtained for arm circumference and the ratio arm circumference: head circumference fell within $95 \%$ confidence limits of the values reported by Sasanow et al. (1986).

Blood samples were collected from the infant at birth (cord blood) and immediately before a mid-morning feed on day 42 by venepuncture with disodium EDTA as anticoagulant. Plasma was immediately separated by centrifugation at $4^{\circ}$, and the erythrocyte pellet was washed three times with normal saline before being frozen until analysis. Samples of breast milk $(5-10 \mathrm{ml})$ were collected at day 5 and day 42, after milk from one breast was expressed with the help of a manual breast pump into a sterile plastic bottle before the time of a mid-morning feed. Fat biopsies were taken at day 5 and day 42 in the upper outer quadrant of either the left or the right buttock (gluteal region) of the lactating mothers, using the aspiration technique, and were treated as previously described by Martin et al. (1991).

All samples were closed under $\mathrm{N}_{2}$ flux into screwcapped glass tubes. Mauritian samples were kept first at $-20^{\circ}$, then transferred to $-80^{\circ}$. The samples were then transported on solid $\mathrm{CO}_{2}$ to our laboratory in France for analysis. French samples were kept frozen at $-80^{\circ}$ until analysis.

\section{Analytical methods}

The analytical methods used in the present study have been described previously (Martin et al. 1991, 1993; Maurage et al. 1998). In brief, triacylglycerols of white adipose tissue and milk samples were extracted and then purified on silica gel G TLC plates as described by Martin et al. (1991). Fatty acids were transmethylated using $\mathrm{BF}_{3}$ in methanol (140 g/l) (Morrisson \& Smith, 1964). Fatty acid methyl esters were extracted in hexane, kept at $-80^{\circ}$ until GC analysis.

Erythrocyte lipids were extracted with isopropanol and chloroform (Rose \& Oklander, 1965) and total phospholipids were separated from neutral lipids with silica cartridges. Further separation of phosphatidylcholine and phosphatidylethanolamine was accomplished by HPLC, and they were then transmethylated (Morrison et al. 1964) and analysed as described by Maurage et al. (1998).

Because we knew that in the case of solvent evaporation to dryness there is complete loss of fatty acid methyl esters with fewer than eight $\mathrm{C}$ atoms and $50 \%$ loss of the fatty acid 10:0, fatty acid methyl esters were extracted in the minimal amount of hexane and no evaporation of the solvent was performed before sample injection into the $\mathrm{GC}$ with flame ionization detection. All fatty acids recorded were expressed as a proportion of total fatty acids $(\mathrm{g} / 100 \mathrm{~g}$ total fatty acids) and levels of dimethylacetals were taken into consideration. 


\section{Statistical analysis}

All data are presented as means with their standard errors. In order to evaluate the population effect and time effect on milk and erythrocyte phospholipid fatty acid compositions, two-factor ANOVA was performed for these samples. Time and population effect were considered as the independent variables and individual fatty acids as the dependent variable.

As previously reported by Martin et al. (1993) the fatty acid composition of white adipose tissue does not change over time during the period of breast-feeding. In our present study, also, it did not change from day 5 to day 42 in either the Mauritian or the French group. Mean values of the results obtained at these two times were calculated for the two groups and were further used for statistical comparison of the population effect using Student's unpaired two-tailed $t$ test.

All correlations were explored by using simple linear regression analysis. All calculations were performed using the statistical software Statview II ${ }^{\mathrm{TM}}$ (Abacus Concepts Inc, ASD Meylan, France).

\section{Results}

\section{Anthropometric measurements}

Table 1 shows data recorded for weight ( $\pm 10 \mathrm{~g})$, length, head circumference, mid-upper-arm circumference $( \pm 0.5 \mathrm{~cm})$ and the arm circumference : head circumference ratio at birth and at day 42 after infants had been breast-fed for a period of 6 weeks. Mauritian infants were longer and had larger arm circumferences and greater arm circumference: head circumference ratios than French infants at birth. All differences except arm circumference : head circumference ratio had disappeared by day 42. Correlations were explored between the anthropometric variables (at birth, at day 42, as well as their variation over the study period) and the contents of arachidonate and docosahexaenoate in erythrocyte phospholipids at birth and day 42 , but none could be found (all $P>0 \cdot 05$ ).

\section{Milk fatty acid composition}

The triacylglycerol content of milk from Mauritian mothers increased from 35.1 (SE 4.8) to 41.0 (SE 8.5) $\mathrm{g} / \mathrm{l}$ from colostrum to mature milk whereas it increased from 31.3 (SE 2.4) to 48.0 (SE 2.9) g/l in milk from French mothers. There was a significant increase due to the time delay between colostrum and mature milk ( $F$ 6.17; $P<0 \cdot 02)$. No significant difference due to the population criterion was noted $(F 0.12 ; P>0 \cdot 7)$.

Table 2 shows the fatty acid composition of milk triacylglycerols obtained from the Mauritian and the French mothers at days 5 and 42 of lactation. There were significant population and time $\times$ population effects when saturated fatty acids were considered. These differences were due to the high content of saturated fatty acids in French mothers' milk at day 42 which mainly rested on the values determined for palmitic acid (16:0) (25.9 (SE 0.6) v. 18.5 (SE 0.7) $\mathrm{g} / 100 \mathrm{~g}$ total fatty acids; French $v$. Mauritian; $P<0.05)$ and for stearic acid (18:0) (7.1 (SE 0.56) v. 5.0 (SE 0.21) g/100 g total fatty acids; French $v$. Mauritian; $P<0.05)$. On the other hand, the fatty acids 10:0 and 12:0 were significantly more represented in Mauritian than French milk whatever the time considered. The sum of monounsaturated fatty acids was 1.4-fold lower in Mauritian than in French milk samples and the levels of the fatty acids 18:1 and 16:1 were responsible for this difference. The sum of monounsaturated fatty acids decreased along with lactation to a similar extent in both populations.

In contrast, the sum of polyunsaturated fatty acids of the two series was twice as high in Mauritian as in French breast milk samples without any time effect. In both colostrum and mature milk, the sum of the fatty acids of the $n-6$ series was significantly more represented in Mauritian than in French samples, with linoleic acid accounting for most of the difference $(23.7-26.9 \%$ v. $11 \cdot 0-11.8 \%$, Mauritian $v$. French respectively). The content of $n-6$ long-chain polyunsaturated fatty acids and specifically that of arachidonic acid (20:4n-6) was also higher in the Mauritian mature

Table 1. Anthropometric data for Mauritian and French infants obtained at birth and after six consecutive weeks of breastfeeding (day 42)

(Mean values and standard deviations)

\begin{tabular}{|c|c|c|c|c|c|c|c|c|}
\hline & & \multicolumn{2}{|c|}{$\begin{array}{c}\text { Mauritian infants } \\
(n 13)\end{array}$} & \multicolumn{2}{|c|}{$\begin{array}{l}\text { French infants } \\
\qquad(n 15)\end{array}$} & \multirow{2}{*}{$\begin{array}{c}\text { Statistical } \\
\text { significance of } \\
\text { difference between } \\
\text { means }\end{array}$} & \multicolumn{2}{|c|}{$\begin{array}{l}\text { Reference } \\
\text { valuest }\end{array}$} \\
\hline & & Mean & $\mathrm{SD}$ & Mean & SD & & Mean & SD \\
\hline Weight (kg) & $\begin{array}{l}\text { Birth } \\
\text { Day } 42\end{array}$ & $\begin{array}{l}3.07 \\
4.31\end{array}$ & $\begin{array}{l}0.30 \\
0.50\end{array}$ & $\begin{array}{l}3.23 \\
4.33\end{array}$ & $\begin{array}{l}0.31 \\
0.62\end{array}$ & $\begin{array}{l}\text { NS } \\
\text { NS }\end{array}$ & $\begin{array}{l}3.34 \\
4.70\end{array}$ & $\begin{array}{l}0.46 \\
0.53\end{array}$ \\
\hline Length (cm) & $\begin{array}{l}\text { Birth } \\
\text { Day } 42\end{array}$ & $\begin{array}{l}51 \cdot 12 \\
55 \cdot 21\end{array}$ & $\begin{array}{l}0.78 \\
1.24\end{array}$ & $\begin{array}{l}49 \cdot 63 \\
55 \cdot 43\end{array}$ & $\begin{array}{l}1.55 \\
2.01\end{array}$ & NS & $\begin{array}{l}49 \cdot 70 \\
56 \cdot 05\end{array}$ & $\begin{array}{l}1.90 \\
2.00\end{array}$ \\
\hline $\mathrm{HC}(\mathrm{cm})$ & $\begin{array}{l}\text { Birth } \\
\text { Day } 42\end{array}$ & $\begin{array}{l}34.04 \\
37.21\end{array}$ & $\begin{array}{l}1.05 \\
1.18\end{array}$ & $\begin{array}{l}34.47 \\
37.99\end{array}$ & $\begin{array}{l}1.24 \\
1.39\end{array}$ & $\begin{array}{l}\text { NS } \\
\text { NS }\end{array}$ & $\begin{array}{l}34.80 \\
38.20\end{array}$ & $\begin{array}{l}1 \cdot 10 \\
1 \cdot 10\end{array}$ \\
\hline $\mathrm{AC}(\mathrm{cm})$ & $\begin{array}{l}\text { Birth } \\
\text { Day } 42\end{array}$ & $\begin{array}{l}10 \cdot 96 \\
12 \cdot 58\end{array}$ & $\begin{array}{l}0.47 \\
0.91\end{array}$ & $\begin{array}{l}10 \cdot 12 \\
12 \cdot 01\end{array}$ & $\begin{array}{l}0.50 \\
1.01\end{array}$ & NS & $\begin{array}{r}9.40 \\
11.33\end{array}$ & $\begin{array}{l}0.75 \\
0.90\end{array}$ \\
\hline$A C: H C$ & $\begin{array}{l}\text { Birth } \\
\text { Day } 42\end{array}$ & $\begin{array}{l}0.32 \\
0.34\end{array}$ & $\begin{array}{l}0.02 \\
0.02\end{array}$ & $\begin{array}{l}0.29 \\
0.32\end{array}$ & $\begin{array}{l}0.00 \\
0.04\end{array}$ & $\begin{array}{l}* * * \\
*\end{array}$ & $\begin{array}{l}- \\
-\end{array}$ & $\begin{array}{l}- \\
-\end{array}$ \\
\hline
\end{tabular}

$\mathrm{AC}$, arm circumference; $\mathrm{HC}$, head circumference.

${ }^{\star} P<0.05,{ }^{* *} P<0.01,{ }^{* \star *} P<0.001$ (Student's unpaired $t$ test).

†Sempé et al. (1979). 
Table 2. Fatty acid composition ( $\mathrm{g} / 100 \mathrm{~g}$ total fatty acids) of breast milk from Mauritian ( $n 13)$ and French $(n 15)$ mothers at days 5 and 42 of breastfeeding

(Mean values with their standard errors)

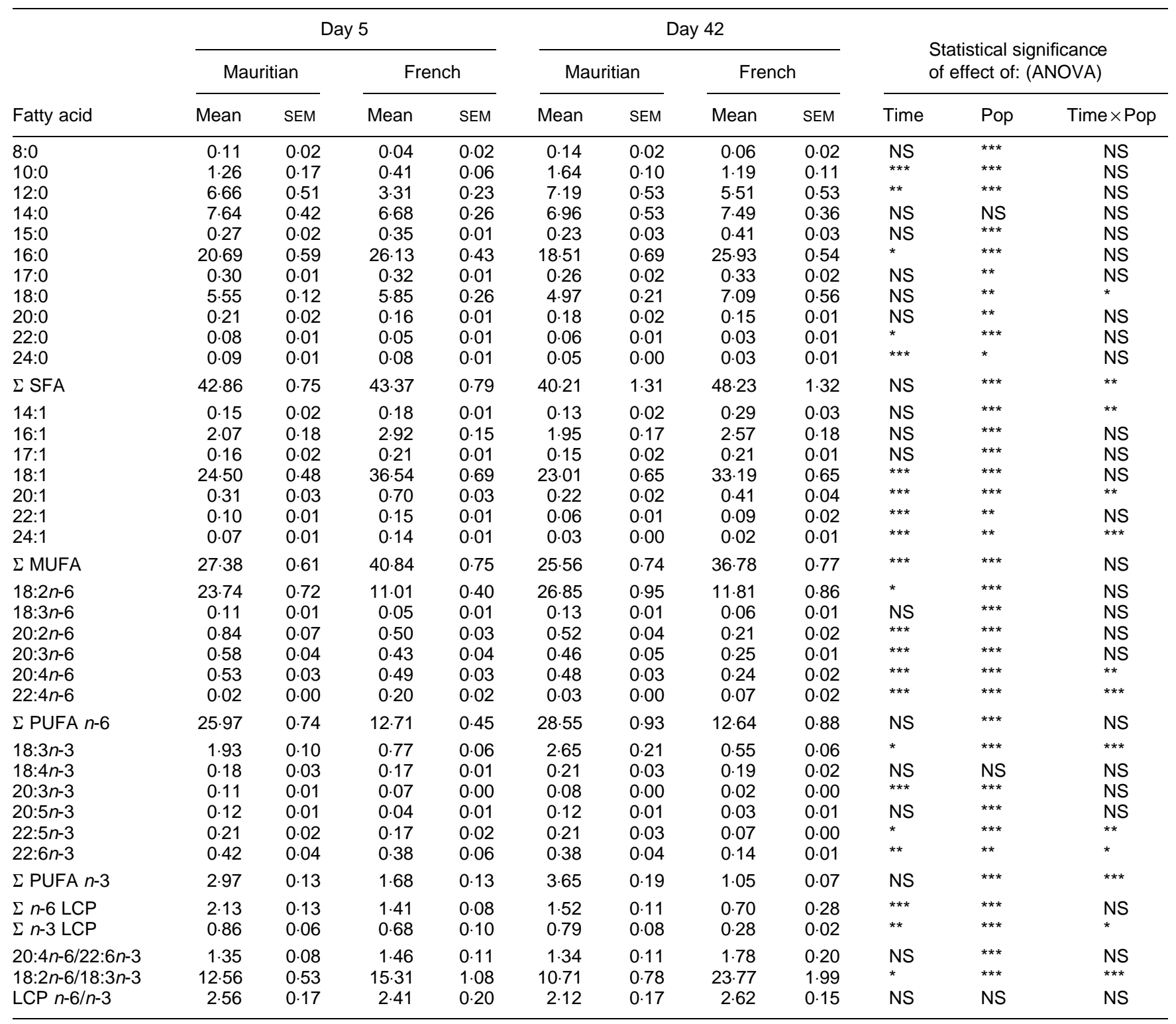

Pop, population; SFA, saturated fatty acids; MUFA, monounsaturated fatty acids; PUFA, polyunsaturated fatty acids; $L C P$, long-chain polyunsaturated fatty acids ( $\geq C_{20}$ ). ${ }^{\star} P<0.05,{ }^{* *} P<0.01,{ }^{* \star *} P<0.001$.

milk. As far as the sum of the fatty acids of the $n-3$ series was concerned, there was a $2 \cdot 5-3 \cdot 5$-fold greater content of $\alpha$-linolenic acid in Mauritian milk than in French milk. $\alpha$-linolenic acid represented means of 1.9 and $2.7 \mathrm{~g} / 100 \mathrm{~g}$ total fatty acids in Mauritian colostrum and mature milk respectively. The values obtained for French samples were 0.8 and $0.6 \mathrm{~g} / 100 \mathrm{~g}$ total fatty acids respectively. In the same way, eicosapentaenoic acid (20:5n-3) was also significantly more represented in Mauritian than in French colostrum and mature milk. Mean levels of docosahexaenoic acid (22:6n-3) were significantly higher in Mauritian than in French mature milk.

Values for the ratios arachidonic acid: docosahexaenoic acid and linoleic acid : $\alpha$-linolenic acid were significantly lower in both Mauritian colostrum and mature milk compared with French (Table 2). In addition, the $n-6: n-3$ longchain polyunsaturated fatty acid ratio was not different between the two populations.

\section{White adipose tissue composition}

Table 3 displays the total fatty acid composition of white adipose tissue triacylglycerol of lactating Mauritian and French mothers. Significant differences were found between the two populations considered for all classes of fatty acids determined. 
Table 3. Fatty acid composition ( $\mathrm{g} / 100 \mathrm{~g}$ total fatty acids) of white adipose tissue from Mauritian ( $n$ 13) and French ( $n$ 15) mothers during the breast-feeding period $\dagger$

(Mean values with their standard errors)

\begin{tabular}{|c|c|c|c|c|c|}
\hline \multirow[b]{2}{*}{ Fatty acids } & \multicolumn{2}{|c|}{ Mauritian } & \multicolumn{2}{|c|}{ French } & \multirow{2}{*}{$\begin{array}{c}\text { Statistical } \\
\text { significance of } \\
\text { difference between } \\
\text { means: } P \ddagger\end{array}$} \\
\hline & Mean & SEM & Mean & SEM & \\
\hline $10: 0$ & 0.15 & 0.07 & 0.08 & 0.03 & NS \\
\hline $12: 0$ & 0.35 & 0.09 & 0.37 & 0.03 & NS \\
\hline $14: 0$ & 1.79 & 0.20 & 3.24 & 0.14 & $* * *$ \\
\hline $15: 0$ & 0.27 & 0.04 & 0.36 & 0.02 & NS \\
\hline $16: 0$ & 17.98 & 1.07 & 21.61 & 0.42 & $* *$ \\
\hline $17: 0$ & 0.11 & 0.04 & 0.25 & 0.02 & ** \\
\hline 18:0 & $2 \cdot 88$ & 0.49 & 3.73 & 0.20 & NS \\
\hline $20: 0$ & 0.07 & 0.03 & 0.11 & 0.01 & NS \\
\hline $22: 0$ & 0.01 & 0.01 & 0.01 & 0.00 & NS \\
\hline$\Sigma$ SFA & 23.64 & 1.54 & $29 \cdot 75$ & 0.67 & $* *$ \\
\hline $14: 1$ & 0.29 & 0.06 & 0.47 & 0.03 & * \\
\hline $16: 1$ & 5.69 & 0.44 & $7 \cdot 10$ & 0.35 & * \\
\hline $17: 1$ & 0.21 & 0.04 & 0.39 & 0.02 & $\star \star \star *$ \\
\hline $18: 1$ & 32.72 & 0.98 & $46 \cdot 14$ & 0.53 & $* * *$ \\
\hline $20: 1$ & 0.33 & 0.06 & 0.62 & 0.03 & $* * *$ \\
\hline $22: 1$ & 0.10 & 0.06 & 0.12 & 0.02 & NS \\
\hline$\Sigma$ MUFA & 39.44 & $1 \cdot 27$ & 54.84 & 0.75 & $* * *$ \\
\hline $18: 2 n-6$ & 29.60 & $1 \cdot 12$ & 13.68 & 0.44 & $* * *$ \\
\hline $18: 3 n-6$ & 0.28 & 0.07 & 0.08 & 0.01 & * \\
\hline $20: 2 n-6$ & 0.90 & 0.29 & 0.14 & 0.01 & * \\
\hline $20: 3 n-6$ & 0.24 & 0.04 & 0.12 & 0.01 & * \\
\hline $20: 4 n-6$ & 0.28 & 0.05 & 0.22 & 0.02 & NS \\
\hline $22: 2 n-6$ & 0.22 & 0.17 & 0.04 & 0.03 & NS \\
\hline $22: 4 n-6$ & 0.07 & 0.01 & 0.05 & 0.01 & NS \\
\hline$\Sigma$ PUFA $n-6$ & 32.47 & $1 \cdot 31$ & 14.32 & 0.47 & $* * *$ \\
\hline $18: 3 n-3$ & 1.74 & 0.13 & 0.40 & 0.03 & $* * *$ \\
\hline $18: 4 n-3$ & 0.04 & 0.02 & 0.18 & 0.02 & $* * *$ \\
\hline $20: 4 n-3$ & 0.02 & 0.01 & 0.04 & 0.03 & NS \\
\hline $20: 5 n-3$ & 0.02 & 0.00 & 0.02 & 0.00 & NS \\
\hline $22: 5 n-3$ & 0.08 & 0.02 & 0.07 & 0.01 & NS \\
\hline $22: 6 n-3$ & 0.07 & 0.02 & 0.08 & 0.02 & NS \\
\hline$\Sigma$ PUFA $n-3$ & $2 \cdot 87$ & 0.49 & 0.80 & 0.07 & $* *$ \\
\hline $18: 2 n-6 / 18: 3 n-3$ & 17.93 & $1 \cdot 15$ & $37 \cdot 27$ & 3.08 & $* * *$ \\
\hline
\end{tabular}

SFA, saturated fatty acids; MUFA, monounsaturated fatty acids; PUFA, polyunsaturated fatty acids. ${ }^{*} P<0.05,{ }^{* *} P<0.01,{ }^{* * *} P<0.001$.

† Values for day 5 and day 42 were averaged for each population.

$\ddagger$ Student's unpaired $t$ test.

Concerning the saturated and monounsaturated fatty acids, significantly lower contents were noted in Mauritian mothers ( $-20 \%$ and $-28 \%$ respectively) essentially due to myristic acid (14:0) and palmitic acid (16:0) in the former class and oleic acid (18:1) in the latter (1.4-fold lower content, as observed in milk). Palmitic acid (16:0) accounted for approximately $75 \%$ of all saturated fatty acids in both populations, and oleic acid (18:1) represented only about $33 \%$ of total fatty acids in Mauritian mothers and $46 \%$ of total fatty acids in the French mothers.

Concerning polyunsaturated fatty acids, significant differences were found for both the $n-6$ and $n-3$ series, and were generally due to the parent essential fatty acids which were present at quite high levels in the Mauritian white adipose tissue samples. Linoleic acid (18:2n-6) represented more than twice the amount observed in French adipose tissue (29.6 (SE 1.12) v. 13.68 (SE 0.44) g/100 g total fatty acids; $P<0.001)$ and in the same way $\alpha$-linolenic acid (18:3n-3) was present at 4-fold higher levels (1.74 (SE 0.13) v. 0.40 (SE 0.03$) \mathrm{g} / 100 \mathrm{~g}$ total fatty acids; $P<0.001$ ). The linoleic acid: $\alpha$-linolenic acid ratio was 2 -fold lower in Mauritian adipose tissue. Significant correlations were observed for linoleic acid between either colostrum $(y=$ $\left.6 \cdot 2 x+9 \cdot 3 ; R^{2} 0.61 ; P<0.001\right)$ or mature milk $(y=7 \cdot 2 x+$ $\left.9.4 ; R^{2} 0.63 ; P<0.001\right)$ and white adipose tissue. Significant correlations were also observed for $\alpha$-linolenic acid between either colostrum $\left(y=0.62 x+0.58 ; R^{2} 0.61 ; P<\right.$ $0 \cdot 001)$ or mature milk $\left(y=1 \cdot 19 x+0 \cdot 15 ; R^{2} 0 \cdot 62 ; P<0 \cdot 001\right)$ and white adipose tissue.

\section{Fatty acid composition of erythrocyte phosphatidylethanolamine of breast-fed infants}

The polyunsaturated fatty acid compositions of erythrocyte phosphatidylethanolamine samples are summarized in Table 4. Significant time-dependent changes were noted 
Table 4. Fatty acid composition ( $\mathrm{g} / 100 \mathrm{~g}$ total fatty acids $\dagger$ ) of erythrocyte phosphatidylethanolamine obtained from Mauritian ( $n$ 13) and French ( $n$ 15) infants at birth and after $42 \mathrm{~d}$ of exclusive breast-feeding

(Mean values with their standard errors)

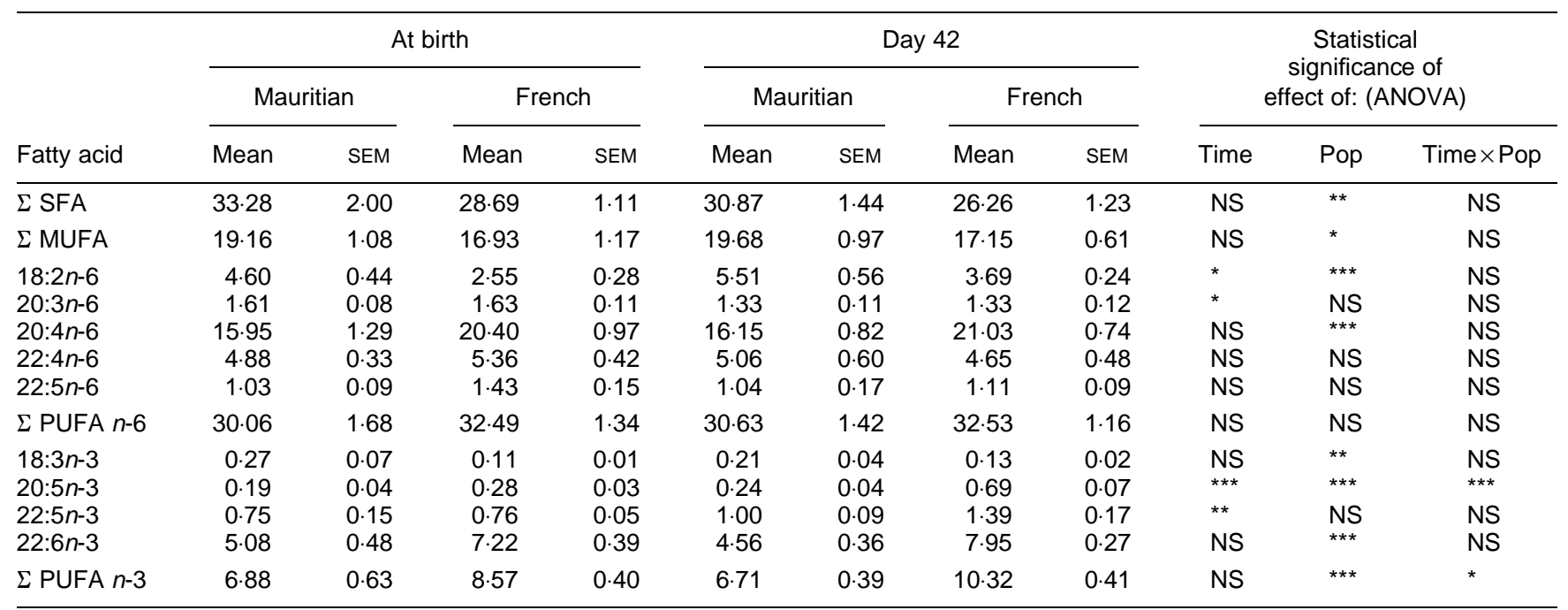

Pop, population; SFA, saturated fatty acids; MUFA, monounsaturated fatty acids; PUFA, polyunsaturated fatty acids.

${ }^{*} P<0.05,{ }^{* *} P<0.01,{ }^{* \star *} P<0.001$.

† Dimethylacetals were included in total fatty acids and represented between 6 and $17 \mathrm{~g} / 100 \mathrm{~g}$.

for the fatty acids $18: 2 n-6,20: 5 n-3$ and $22: 5 n-3$. The level of linoleic acid was 1.5-1.7-fold higher in Mauritian than in French infants and this difference was significant for the two ages $(P<0.001)$. There was a significant increase in linoleic acid with time in both populations. Conversely there was a $25 \%$ lower concentration of arachidonic acid in samples from Mauritian compared with French infants either at birth or at day 42. In addition $\alpha$-linolenic acid was twice as high in samples from Mauritian than French infants. In contrast both eicosapentaenoic acid and docosahexaenoic acid levels were lower. Within each population there was no significant difference in the docosahexaenoic acid level between the time of birth and day 42 .
Fatty acid composition of erythrocyte phosphatidylcholine samples from breast-fed infants

The polyunsaturated fatty acid compositions of erythrocyte phosphatidylcholine samples are shown in Table 5. As for phosphatidylethanolamine, similar time-dependent changes were observed in phosphatidylcholine with an additional increase of $\alpha$-linolenic acid. Mean linoleic acid concentration increased significantly with lactation within each population. The population effect was close to significance $(P<0.08)$. This was due to the increase in erythrocyte phosphatidylcholine linoleic acid content in French infants from birth $(7.6 \%)$ to day $42(16.4 \%)$. Mean arachidonic acid

Table 5. Fatty acid composition (g/100 g total fatty acids) of erythrocyte phosphatidylcholine obtained from Mauritian ( $n$ 13) and French ( $n$ 15) infants at birth and after $42 \mathrm{~d}$ of exclusive breast-feeding

(Mean values with their standard errors)

\begin{tabular}{|c|c|c|c|c|c|c|c|c|c|c|c|}
\hline \multirow[b]{2}{*}{ Fatty acid } & \multicolumn{4}{|c|}{ At birth } & \multicolumn{4}{|c|}{ Day 42} & \multicolumn{3}{|c|}{$\begin{array}{c}\text { Statistical } \\
\text { significance of } \\
\text { effect of: (ANOVA) }\end{array}$} \\
\hline & Mean & SEM & Mean & SEM & Mean & SEM & Mean & SEM & Time & Pop & Time $\times$ Pop \\
\hline$\Sigma$ SFA & 58.45 & 1.87 & $50 \cdot 27$ & 0.46 & $56 \cdot 20$ & 3.05 & 47.73 & 0.48 & NS & $* \star *$ & NS \\
\hline$\Sigma$ MUFA & 19.61 & 1.37 & $20 \cdot 13$ & 0.99 & 18.41 & 0.75 & $18 \cdot 75$ & 0.31 & NS & NS & NS \\
\hline $\begin{array}{l}18: 2 n-6 \\
20: 3 n-6 \\
20: 4 n-6 \\
22: 4 n-6 \\
22: 5 n-6\end{array}$ & $\begin{array}{l}8.33 \\
2.01 \\
5.36 \\
0.34 \\
0.22\end{array}$ & $\begin{array}{l}1 \cdot 13 \\
0.27 \\
0.74 \\
0.04 \\
0.10\end{array}$ & $\begin{array}{r}7.56 \\
3.13 \\
11.73 \\
0.70 \\
0.51\end{array}$ & $\begin{array}{l}0.22 \\
0.23 \\
0.92 \\
0.09 \\
0.08\end{array}$ & $\begin{array}{r}11.75 \\
1.17 \\
3.91 \\
0.48 \\
0.11\end{array}$ & $\begin{array}{l}1.80 \\
0.25 \\
0.83 \\
0.07 \\
0.03\end{array}$ & $\begin{array}{r}16.38 \\
2.37 \\
8.64 \\
0.43 \\
0.27\end{array}$ & $\begin{array}{l}0.74 \\
0.10 \\
0.44 \\
0.06 \\
0.03\end{array}$ & $\begin{array}{l}* * * \\
* * * \\
* * \\
\text { NS }\end{array}$ & $\begin{array}{l}\text { NS } \\
* * * \\
* * * \\
* \\
* *\end{array}$ & $\begin{array}{l}{ }^{*} \\
\text { NS } \\
\text { NS } \\
\text { NS }\end{array}$ \\
\hline$\Sigma$ PUFA $n-6$ & $17 \cdot 81$ & 1.77 & $24 \cdot 11$ & 1.23 & 18.64 & 2.56 & 28.59 & 0.60 & NS & $* * *$ & NS \\
\hline $\begin{array}{l}18: 3 n-3 \\
20: 5 n-3 \\
22: 5 n-3 \\
22: 6 n-3\end{array}$ & $\begin{array}{l}0.16 \\
0.20 \\
0 \cdot 10 \\
3 \cdot 14\end{array}$ & $\begin{array}{l}0.05 \\
0.05 \\
0.03 \\
0.48\end{array}$ & $\begin{array}{l}0.03 \\
0.21 \\
0.25 \\
3.67\end{array}$ & $\begin{array}{l}0.01 \\
0.03 \\
0.02 \\
0.25\end{array}$ & $\begin{array}{l}0.28 \\
0.23 \\
0.31 \\
3.34\end{array}$ & $\begin{array}{l}0.07 \\
0.03 \\
0.10 \\
0.56\end{array}$ & $\begin{array}{l}0.13 \\
0.35 \\
0.39 \\
2.88\end{array}$ & $\begin{array}{l}0.02 \\
0.04 \\
0.03 \\
0.22\end{array}$ & $\begin{array}{l}* \\
* \\
* * \\
\text { NS }\end{array}$ & $\begin{array}{l}* * \\
\text { NS } \\
\text { NS }\end{array}$ & $\begin{array}{l}\text { NS } \\
\text { NS } \\
\text { NS } \\
\text { NS }\end{array}$ \\
\hline
\end{tabular}

Pop, population; SFA, saturated fatty acids; MUFA, monounsaturated fatty acids; PUFA, polyunsaturated fatty acids.

${ }^{\star} P<0.05,{ }^{* *} P<0.01,{ }^{* *} P<0.001$. 
levels were significantly lower in samples from Mauritian than from French infants and there was a significant timedependent decrease in both populations. Mean $\alpha$-linolenic acid levels were significantly higher in Mauritian than in French samples and increased significantly with time in both populations. The differences seen in eicosapentaenoic acid were due to the increase observed from day 0 to day 42 in French infants. There was no significant effect of time, population or time $\times$ population interaction concerning levels of docosahexaenoic acid.

\section{Discussion}

Though Mauritius is geographically considered as an African country, more than $60 \%$ of the Mauritian multi-ethnic population is of Indian origin and descends from migrants from the Indian subcontinent who arrived three generations ago. The subjects included in the current study belonged to this ethnic group. To date, there have been few studies which have reported the fatty acid composition of human milk from Asian subjects or those from the Indian subcontinent (Kneebone et al. 1985; Chulei et al. 1995; Chen et al. 1997). The present study brings further information regarding the milk fatty acid composition of women of Indian origin and reports for the first time data obtained from Mauritian human milk.

From our comparative study, the differences observed in fatty acid composition of white adipose tissue and milk samples are consistent with what could be expected from the dietary habits of these two distinct populations. The IndoMauritian group had a predominantly vegetarian diet with high intakes of vegetable proteins as pulses and grains and little animal protein. This group had a lower animal and a higher vegetable fat intake as well. A recent statistical evaluation of the Mauritian per capita dietary consumption over the year 1996 reported that carbohydrate constituted $65 \%$ of the daily energy intake while fat and protein constituted $24 \%$ and $11 \%$ daily energy intake respectively. Carbohydrate of cereal origin constituted $65 \%$ of total carbohydrate intake. As expected, fat and protein were predominantly of vegetable sources. Vegetable fat accounted for $68.5 \%$ total daily fat intake while vegetable protein accounted for $58 \%$ total daily protein intake (data obtained for the year 1996 from the Mauritian Government Department of Statistics, personal communication). Concerning French dietary intakes, a recent report (Rigaud et al. 1997) following a nationwide study conducted in France between 1993 and 1994 evaluated the macronutrient intake of the typical French diet, and reported that in adults the total carbohydrate constituted between 36 and $40 \%$ of the daily energy intake while protein and fat constituted $17-18 \%$ and $39-40 \%$ respectively of total daily energy intake. Higher levels of animal protein and fat are consumed in France compared with Mauritius, and according to another study (Lecerf et al. 1993) conducted in pregnant women from a maternity hospital in the North of France, more than $70 \%$ of their protein intake and more than $70 \%$ of their fat intake were of animal origin.

Saturated fatty acids were lower in milk and white adipose tissue of Mauritian mothers than French mothers with the fatty acids 16:0 and 18:0 accounting for most of the differences in both tissues. These two fatty acids are normally abundant in animal fat and scarce in most vegetable fat. It has also been suggested that the fatty acid 18:0 may decrease in milk fat after high intakes of carbohydrate (Finley et al. 1985). In addition higher levels of the fatty acids 10:0 and 12:0 were found in milk and white adipose tissue of Mauritians compared with French mothers. Such findings have already been reported in mothers consuming vegetarian diets (Specker et al. 1987). The lower content of monounsaturated fatty acids in Mauritian mothers, particularly of the fatty acid 18:1 in Mauritian milk and white adipose tissue, is also compatible with lower animal fat content in the Mauritian diet in comparison with the French diet (Finley et al. 1985). Together with lower consumption of animal fat, poor olive oil and palm oil consumption in the Mauritian population could account for the difference in the fatty acid 18:1 as well. Incidently it is important to stress that since the year 1987, in order to reduce the saturated fat intake in the Mauritian population, the Mauritian government switched from the importation of a commonly used cooking oil that was mostly palm oil to one that is wholly soyabean oil. Soyabean oil contains the fatty acids $18: 2 n-6$ and $18: 3 n-3$ in average proportions of 48.5 and $6.5 \mathrm{~g} / 100 \mathrm{~g}$ total fat respectively and only $22 \mathrm{~g} / 100 \mathrm{~g}$ as oleic acid compared with $39 \mathrm{~g} / 100 \mathrm{~g}$ in palm oil.

Since linoleic acid and $\alpha$-linolenic acid are essential for human beings and are provided by the diet, the particularly high values of these two fatty acids observed in Mauritian compared with French subjects imply their higher dietary intake in vegetable fat by the Mauritians. Indeed, the content of linoleic acid in Mauritian milk and white adipose tissue was twice as high, and that of $\alpha$-linolenic acid was two to four times higher than in the French subjects. A close relationship between linoleic acid contents of the diet, white adipose tissue and milk content has been observed previously by Martin et al. (1993) who reported that linoleic acid contents of diet and white adipose tissue triacylglycerols helped to explain the interindividual variation of the linoleate concentration in both colostrum and mature human milk. The present study confirms the previous correlations found for linoleic acid between milk and white adipose tissues with coefficients of determination of about $60 \%$. Other studies have also reported similar relationships between diet and milk (Vuori et al. 1982; Finley et al. 1985). Along with linoleic acid, levels of $\alpha$-linolenic acid also increase with high consumption of vegetable fat. Our cross-cultural study enables us to consider the wide range over which $\alpha$-linolenic acid varies and allows us to demonstrate that the content of $\alpha$-linolenic acid was significantly correlated between human milk and white adipose tissue. As for linoleic acid, the coefficient of determination was also close to $60 \%$.

Levels of linoleic acid and $\alpha$-linolenic acid which approach closest to the Mauritian milk values have only been reported in the studies conducted in women consuming a vegetarian diet (Sanders et al. 1978; Specker et al. 1987; Sanders \& Reddy, 1992; Jensen, 1996). Other studies of human milk from omnivorous populations consuming non-Western diets have also been shown to provide high levels of essential fatty acids, but none have so far reported values as high for both 
linoleic and $\alpha$-linolenic acid in the same sample as those found in our Mauritian milk (Kneebone et al. 1985; Borschel et al. 1986; Chulei et al. 1995; Chen et al. 1997). Mean concentrations of linoleic acid in milk reaching values greater than $22 \mathrm{~g} / 100 \mathrm{~g}$ total fatty acids have only been reported in Egyptian milk where it represented about $24 \mathrm{~g} / 100 \mathrm{~g}$ total fatty acids, but the mean level of $\alpha$-linolenic acid was closer to values found in French milk samples and not as high as in Mauritian milk (Borschel et al. 1986). Mean values of $\alpha$-linolenic acid up to $2.7 \mathrm{~g} / 100 \mathrm{~g}$ total fatty acids were reported in milk samples from Chinese and Mongolian women living in five different regions of China. Incidently, Chinese populations are also great consumers of soyabean oil. However, the mean value for the fatty acid 18:2n-6 was 5-7\% lower than in our Mauritian milk (Chulei et al. 1995; Chen et al. 1997).

Mauritian milk was also richer in other long-chain fatty acids of the $n-6$ series including 20:2n-6, 20:3n-6, 20:4n-6 and 22:4n-6. However, the concentration of arachidonic acid, an important longer-chain derivative of linoleic acid, in Mauritian milk was quite close to the level found in French milk at day 5 and it did not decrease as considerably as in French milk as lactation progressed. In a similar way docosahexaenoic acid decreased modestly $(-10 \%)$ in Mauritian mature milk while a more important decrease $(-63 \%)$ was observed as French milk matured. Despite differences in the sum of $n-6$ and in the sum of $n-3$ longchain polyunsaturated fatty acids in milk there was constancy in the $n-6: n-3$ long-chain polyunsaturated fatty acid ratio between the French and Mauritian populations. The values obtained in the present study are close to those already reported by others (Guesnet et al. 1993; Martin et al. 1993; Jensen, 1996) and fall within the European recommended ranges (ESPGAN Committee on Nutrition, 1991).

The differences in the dietary habits and in milk fatty acid composition would be expected to lead to different fatty acid compositions of erythrocyte phospholipids of the breast-fed infants. Indeed, linoleic acid and $\alpha$-linolenic acid were more represented in both classes of phospholipid in Mauritian compared with French infants both at birth and after the 6-week period of breast-feeding. In contrast, the $n-6$ and $n-3$ long-chain polyunsaturated fatty acid derivatives which were more abundant in Mauritian than in French milk, were nonetheless lower in the erythrocyte phospholipids of Mauritian infants. Arachidonic acid was 5-7 $\mathrm{g} / 100 \mathrm{~g}$ lower and docosahexaenoic acid was $1-3 \mathrm{~g} / 100 \mathrm{~g}$ lower in Mauritian erythrocyte phospholipids in comparison with French. The difference was maintained over time. These findings are consistent with the hypothesis that high intakes of linoleic acid may lead to competition between linoleic acid, arachidonic acid and docosahexaenoic acid for acylation at the $s n-2$ position of the erythrocyte phospholipid (Makrides et al. 1993; Innis et al. 1996, 1997). This could be a possible explanation for the low incorporation of arachidonic acid and docosahexaenoic acid into the erythrocyte membranes of Mauritian infants. Moreover, it has been suggested that when the diet provides adequate essential fatty acids, further linoleic and $\alpha$-linolenic intakes do not seem to increase tissue concentrations of arachidonic and docosahexaenoic acids respectively (Anding \& Hwang, 1986; Arbuckel et al. 1994).
Despite the large differences observed in the long-chain polyunsaturated fatty acid content of breast-milk and subsequently in the infants' erythrocyte phospholipids, we were unable to find any relationship between erythrocyte phospholipid content of arachidonate or docosahexaenoate and the anthropometric variables in these breast-fed infants. These results are in accordance with reports of Ponder et al. (1992), Innis et al. (1996, 1997) and Birch et al. (1998) who also could not find evidence of relationships over short study periods between longchain polyunsaturated fatty acids of blood lipids and growth variables of infants fed on formulas of different lipid composition. In the same way, differences in fatty acid composition of plasma and cord artery phospholipids were found between infants born to vegetarian and omnivorous mothers, but differences in the docosahexaenoic acid levels in the infants' tissue lipids were not statistically related to their differences in birth weight, head circumference or length (Sanders \& Reddy, 1992). However, this issue is quite controversial. Other authors have reported significant and positive correlations between birth weight and plasma triacylglycerol arachidonate and total long-chain polyunsaturated $n-6$ fatty acid content obtained before complete enteral feeding in 4-d-old premature infants (Koletzko \& Braun, 1991). Carlson et al. (1992) reported a positive correlation between arachidonic acid status and first year growth in premature infants fed on marine-oil-supplemented and non-supplemented formulas.

In summary, the differences observed in the milk fatty acid composition of the two populations we studied are consistent with what was expected in regard to the great differences in the dietary habits of Mauritian and French women. Both parent essential fatty acids and their longerchain derivatives were found in much greater amounts in Mauritian $v$. French milk. Nonetheless, the breast-fed Mauritian infants presented lower levels of long-chain polyunsaturated fatty acids in their erythrocyte phospholipids. This suggests the lack of a simple relationship between the amount of long-chain polyunsaturated fatty acids provided and their accretion in membrane phospholipids when provided concomitantly with high levels of both linoleic and $\alpha$-linolenic acids even though the ratio falls within recommended ranges.

\section{Acknowledgements}

Mrs Pugo-Gunsam is the beneficiary of sponsorship from the French Ministry of Cooperation in Mauritius and the University of Mauritius. The authors thank all Mauritian and French participants in this study for their kind cooperation and are grateful to Dr Lim, Dr Ram, Dr Ramjuttun, $\mathrm{Mr}$ Bundhoo and the staff of Jawaharlall Nehru Hospital, Mauritius for their valuable help in the enrolment of volunteers for this study. The medical and technical staff of Centre Hospitalier Universitaire de Tours, France are equally acknowledged for their precious assistance in recruiting French participants and for French data. This work was partly supported by Groupe Danone, France. 


\section{References}

Anding RH \& Hwang DH (1986) Effects of dietary linolenate on the fatty acid composition of brain lipids in rats. Lipids 21, 697-701.

Arbuckle LD, MacKinnon MJ \& Innis SM(1994) Formula 18:2(n-6) and 18:3(n-3) content and ratio influence long-chain polyunsaturated fatty acids in the developing piglet liver and central nervous system. Journal of Nutrition 124, 289-298.

Birch EE, Hoffman DR, Uauy R, Birch DG \& Prestidge C (1998) Visual acuity and the essentiality of docosahexaenoic acid and arachidonic acid in the diet of term infants. Pediatric Research 44, 201-209.

Borschel MW, Elkin RG, Kirksey A, Story JA, Galal O, Harrison GG \& Jerome NW (1986) Fatty acid composition of mature human milk of Egyptian and American women. American Journal of Clinical Nutrition 44, 330-335.

Carlson SE, Cooke RJ, Werkman SH \& Tolley EA (1992) First year growth of preterm infants fed standard compared to marine oil $n-3$ supplemented formula. Lipids 27, 901-907.

Chen ZY, Kwan KK, Tong KK, Ratnayake WMN, Li HQ \& Leung SSF (1997) Breast milk fatty acid composition: a comparative study between Hong Kong and Chongqing Chinese. Lipids 32, 1061-1067.

Chulei R, Xiaofang L, Hongsheng M, Xiulan M, Guizheng L, Gianhong D, DeFrancesco CA \& Connor WE (1995) Milk composition in women from five different regions of China: the great diversity of milk fatty acids. Journal of Nutrition $\mathbf{1 2 5}$, 2993-2998.

Connor WE, Neuringer M \& Lin DS (1990) Dietary effects on brain fatty acid composition: the reversibility of $n-3$ fatty acid deficiency and turnover of docosahexaenoic acid in the brain, erythrocytes, and plasma of rhesus monkeys. Journal of Lipid Research 31, 237-247.

ESPGAN Committee on Nutrition (1991) Committee report. Comment on the content and composition of lipids in infant formulas. Acta Paediatrica Scandinavica 80, 887-896.

Field CJ, Angel A \& Clandinin MT (1985) Relationship of diet to the fatty acid composition of human adipose tissue structural and stored lipids. American Journal of Clinical Nutrition 42, 12061220.

Finley DA, Lönnerdal B, Dewey KG \& Grivetti LE (1985) Breast milk composition: fat content and fatty acid composition in vegetarians and non-vegetarians. American Journal of Clinical Nutrition 41, 787-800.

Guesnet P, Antoine J-M, Rochette de Lempdes J-B, Galent A \& Durand G (1993) Polyunsaturated fatty acid composition of human milk in France: changes during the course of lactation and regional differences. European Journal of Clinical Nutrition, 47, 700-710.

Hirsch J, Farquhar JW, Ahrens EH, Peterson ML \& Stoffel W (1960) Studies of adipose tissue in man. A microtechnic for sampling and analysis. American Journal of Clinical Nutrition $\mathbf{8}$, 499-511.

Innis SM, Akrabawi SS, Diersen-Schade DA, Dobson V \& Guy DG (1997) Visual acuity and blood lipids in term infants fed human milk or formulae. Lipids 32, 63-72.

Innis SM, Auestad N \& Siegman JS (1996) Blood lipid docosahexaenoic and arachidonic acid in term gestation infants fed formulas with high docosahexaenoic acid, low eicosapentaenoic acid fish oil. Lipids 31, 617-625.

Jensen RG (1996) The lipids in human milk. Progress in Lipid Research 35, 53-92.

Kneebone GM, Kneebone R \& Gibson RA (1985) Fatty acid composition of breast milk from three racial groups from Penang, Malaysia. American Journal of Clinical Nutrition 41, 765-769.
Koletzko B \& Braun M (1991) Arachidonic acid and early human growth: is there a relation? Annals of Nutrition and Metabolism 35, 128-131.

Lecerf JM, Debeugny-Lecerf B, Fantino M, Isorez D, Marecaux N \& Delcroix M (1993) Enquête alimentaire auprès de 50 femmes enceintes dans le Nord de la France (Diet survey in fifty pregnant women from the Northern region of France). Cahiers de Nutrition et de Diététique 28, 350-358.

Makrides M, Simmer K, Goggin M \& Gibson RA (1993) Erythrocyte docosahexaenoic acid correlates with the visual response of healthy, term infants. Pediatric Research 34, 425-427.

Martin JC, Bougnoux P, Fignon A, Theret V, Antoine JM, Lamisse F \& Couet C (1993) Dependence of human milk essential fatty acids on adipose stores during lactation. American Journal of Clinical Nutrition 58, 653-659.

Martin JC, Niyongabo T, Moreau L, Antoine JM, Lanson M, Berger C, Lamisse F, Bougnoux P \& Couet C (1991) Essential fatty acid composition of human colostrum triglycerides: its relationship with adipose tissue composition. American Journal of Clinical Nutrition 54, 829-835.

Maurage C, Guesnet P, Pinault M, Rochette de Lempdes J, Durand G, Antoine J \& Couet C (1998) Effect of two types of fish oil supplementation on plasma and erythrocyte phospholipids in formula-fed infants. Biology of the Neonate 74, 416-429.

Morrison W \& Smith LM (1964) Preparation of fatty acid methyl esters and dimethylacetals from lipids with boron fluoridemethanol. Journal of Lipid Research 5, 600-608.

Neville MC \& Picciano MF (1997) Regulation of milk lipid secretion and composition. Annual Review of Nutrition 17, 159-184.

Ponder DL, Innis SM, Benson JD \& Siegman JS (1992) Docosahexaenoic acid status of term infants fed breastmilk or infant formula containing soy oil or corn oil. Pediatric Research 32, 683-688.

Rigaud D, Giachetti I, Deheeger M, Borys JM, Volatier JL, Lemoine A \& Cassuto DA (1997) Enquête Française de consommation alimentaire I: energie et macronutrients (French diet survey I: energy and macronutrients). Cahiers de Nutrition et de Diététique 32, 379-389.

Rose HG \& Oklander M (1965) Improved procedure for the extraction of lipids from human erythrocytes. Journal of Lipid Research 6, 428-431.

Sanders TAB, Ellis FR \& Dickerson JWT (1978) Studies of vegans; the fatty acid composition of plasma choline phosphoglycerides, erythrocytes, adipose tissue, and breastmilk, and some indicators of susceptibility to ischemic heart disease in vegans and omnivore controls. American Journal of Clinical Nutrition 31, 805-813.

Sanders TAB \& Reddy S (1992) The influence of a vegetarian diet on the fatty acid composition of human milk and the essential fatty acid status of the infant. Journal of Pediatrics 120, S71-S77.

Sasanow SR, Georgieff MK \& Pereira GR (1986) Mid-arm circumference and mid-arm/head circumference ratios: standard curves for anthropometric assessment of neonatal nutritional status. Journal of Pediatrics 109, 311-315.

Sempé M, Pedron G \& Roy-Pernot MP (1979) In Auxologie: Methodes et Sequences (Auxology: Methods and Sequences), pp. 28-103. Paris: Theraplix.

Specker BL, Wey HE \& Miller DJ (1987) Differences in fatty acid composition of human milk in vegetarian and nonvegetarian women: long-term effect of diet. Journal of Pediatric Gastroenterology and Nutrition 6, 764-768.

Vuori E, Kiuru K, Makinen SM, Vayrynen P, Kara R \& Kuitunen P (1982) Material diet and fatty acid pattern of breast milk. Acta Paediatrica Scandinavica 71, 959-963. 